Article

\title{
The Effect of Lightweight Concrete Cores on the Thermal Performance of Vacuum Insulation Panels
}

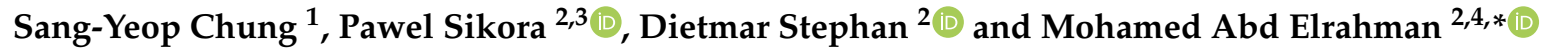 \\ 1 Department of Civil and Environmental Engineering, Sejong University, Seoul 05006, Korea; \\ sychung@sejong.ac.kr \\ 2 Building Materials and Construction Chemistry, Technische Universität Berlin, Gustav-Meyer-Allee 25, \\ 13355 Berlin, Germany; pawel.sikora@zut.edu.pl (P.S.); stephan@tu-berlin.de (D.S.) \\ 3 Faculty of Civil Engineering and Architecture, West Pomeranian University of Technology Szczecin, \\ Al. Piastow 50, 70-311 Szczecin, Poland \\ 4 Structural Engineering Department, Mansoura University, Elgomhouria St., Mansoura City 35516, Egypt \\ * Correspondence: mohamedattia@mans.edu.eg; Tel.: +20-109-316-6858
}

Received: 6 May 2020; Accepted: 4 June 2020; Published: 9 June 2020

check for updates

\begin{abstract}
The performance of vacuum insulation panels (VIPs) is strongly affected by several factors, such as panel thickness, design, quality of vacuum, and material type. In particular, the core materials inside VIPs significantly influence their overall performance. Despite their superior insulation performance, VIPs are limited in their widespread use as structural materials, because of their low material strength and the relatively expensive core materials. As an alternative core material that can compensate these limitations, foamed concrete, a type of lightweight concrete with very low density, can be used. In this study, two different types of foamed concrete were used as VIP core materials, with their effects on the thermal behavior of the VIPs having been evaluated using experimental and numerical methods. To confirm and generate numerical models for VIP analysis, micro-computed tomography (micro-CT) was utilized. The obtained results show that insulation effects increase effectively when panels with lightweight concrete are in a vacuum, and both foamed concrete types can be effectively used as VIP core materials.
\end{abstract}

Keywords: lightweight concrete; foam concrete; vacuum insulation panel (VIP); micro-CT; thermal properties

\section{Introduction}

A vacuum Insulation Panel (VIP) is a system for thermal insulation which consists of an enclosed rigid core and a surrounding membrane. In general, the thermal conductivity of VIPs is about 5 to 10 times lower than other insulation materials or systems [1,2]. There has recently been growing interest in energy efficiency, with the reduction of energy consumption through heat loss having become an important issue in most industries, especially the building sector. To satisfy energy requirements in the construction field, new insulating materials with a high porosity and with reduced material densities have been developed, but further reduction in thermal conductivity is still desirable for more effective insulation [3-5]. While VIPs are also being used in buildings for insulation purposes, there are limitations in their widespread application because of the relatively expensive insulation techniques involved, as compared to other insulations [6], such as mineral wool and foamed polystyrene $[7,8]$. In order to overcome price limitations, a method for reducing VIP production costs is needed.

VIPs are generally composed of two parts: a membrane and a core material. More specifically, VIPs are generally flat and consist of an enclosure or membrane, which are often metalized or laminates made of welded metal and plastic foils, and a core material. The core materials need to be open-porous 
for effective evacuation, and they need to be capable of withstanding the external load caused by atmospheric pressure and a gas tight envelope, to maintain the required vacuum quality in the production process $[9,10]$. In addition, they must have long-term stability to be used in buildings. It is well known that relatively expensive materials, such as fumed silica or precipitated silica, are currently used for VIP manufacturing, and these contribute to high costs [11]. Therefore, the use of alternative low cost materials for the VIPs is critical to overcome the overall challenge of high cost.

Concrete and cement-based materials are the most widely used materials in the construction industry, due to advantages, such as low cost, high strength, water resistance, convenient production, as well as multiple applications [12,13]. Compared with the conventional core materials of VIPs, concrete is an economical and versatile material that has advanced mechanical properties, such as compressive strength; the use of concrete for VIPs can therefore reduce production costs. The main role of VIPs is to enhance thermal insulation, with VIPs needing to have low thermal conductivity and a high-porous structure [14]. Among the various cement-based composites, lightweight concrete is a widely used material containing numerous pores within the material and has a density less than $2000 \mathrm{~kg} / \mathrm{m}^{3}$, which is lower than that of normal concrete [15,16]. In addition, lightweight concrete has a relatively higher stiffness and strength than conventional VIP core materials.

Lightweight concrete has itself been widely utilized for insulation purposes [17,18]. In general, it is mainly produced by using either lightweight aggregates [19-21], or foaming agents [22-24], which are called lightweight aggregate concrete and foamed concrete, respectively. Lightweight aggregate concrete contains more than $50 \mathrm{vol}$ \% lightweight aggregates in the concrete volume, while foamed concrete is a cellular material with a highly porous structure. It has been found that lightweight aggregate concrete has a relatively higher strength than foamed concrete, but that foamed concrete demonstrates lower thermal conductivity than lightweight aggregate concrete at the same density level [25]. Foamed concrete is thus more suitable than other lightweight concrete for use as a VIP core since the core material must be a porous media so as to be suitable for evacuation processes. Foamed concrete has very low density ranges, between 200 and $1600 \mathrm{~kg} / \mathrm{m}^{3}$, and with a compressive strength of 0.2 to $15 \mathrm{MPa}$, which is higher than that of the core materials of ordinary VIPs [26,27].

The main purpose of this research was to evaluate the effect of lightweight foamed concrete as a core material on the performance of VIPs. For this purpose, foamed concrete was produced and utilized as the core material for the target VIP. The most important requirements of the core are a porous structure for evacuation, as well as insulation related properties, with the material also needing to have the appropriate strength and stability to withstand the pressure in the vacuum process. Thus, in addition to the pure foamed concrete, another foamed concrete specimen incorporating lightweight aggregate for better strength was also designed and used. VIP specimens with lightweight concrete cores were then manufactured using a membrane and the same procedures as commercial VIP specimens. To confirm the insulation performance of the vacuumed lightweight concrete, the thermal conductivity of the lightweight concrete specimens before and after evacuation was experimentally and numerically measured and compared using standardized measurement devices and finite element analysis, respectively. To visualize and generate the numerical model, micro-computed tomography (micro-CT), a nondestructive method, was used, with the microstructures of the used core materials being subsequently examined [28-30]. Following on from the obtained results, the effects of lightweight concrete as a core material are examined and discussed below.

\section{Sample Preparation}

This study focuses on the effects of lightweight concrete on the insulation performance of VIPs, and the appropriate selection of material for the core part of the VIP is important. The core material needs to be porous and have sufficient strength to withstand pressure for effective evacuation. Among several types of lightweight concretes, foamed concrete, which contains numerous pores, was selected. In addition to the pure foamed concrete, another type of foamed concrete containing lightweight aggregates was also prepared and used as a core material. Despite its versatility in insulation, pure 
foamed concrete with very low density has a relatively low strength and stability in comparison to other types of lightweight concretes including lightweight aggregate concrete. Since conventional lightweight aggregate concrete contains less pores than foamed concrete, it is not an appropriate VIP core material. Alternatively, foamed concrete incorporating lightweight aggregates can be used as the core material, reducing shrinkage and enhancing material strength.

\subsection{Core Materials}

Two different types of lightweight foamed concrete were used in this study: pure foamed concrete and foamed concrete with lightweight aggregates (LWAs). The former specimen was a type of pure foamed concrete, while the latter contained lightweight aggregates (Liaver $\left.{ }^{\circledR}\right)$ for better strength and less shrinkage. The VIP specimens with pure foamed concrete were denoted as ' $\mathrm{FCP}^{\prime}$, while foamed concrete with lightweight aggregates was denoted as 'FCA'. Two mixes with similar compositions, but with different densities $\left(250 \mathrm{~kg} / \mathrm{m}^{3}\right.$ (FCP) and $350 \mathrm{~kg} / \mathrm{m}^{3}$ (FCA)), were prepared and examined.

The cement used in this investigation is CEM I 52.5 R conforming EN 197-1 produced by Heidelberg Cement (Heidelberg, Germany). Hard coal fly ash type C (EFA-Füller, Baumineral GmbH, Germany) conforming EN 450-1 was used as a cement replacement (FA); cement was replaced with $30 \mathrm{wt} . \%$ of FA. To produce the FCA specimen with lightweight aggregates, fine expanded glass (Liaver ${ }^{\circledR}, 0.1-0.3 \mathrm{~mm}$ ) was added. Chemical and physical characteristics of the used binder are summarized in Table 1. For both mixes, the water-binder ratio $(\mathrm{w} / \mathrm{b})$ was fixed at 0.4 , while the ratio of foam:paste was fixed at 3:1 and 4:1 to produce materials with two different densities. The used foaming agent was Lightcrete 400 provided by Sika Germany (Stuttgart, Germany). A compatible type of PCE superplasticizer (tailor-made Sika Viscocrete) without destroying the foam bubbles was used to achieve a workable foamed concrete with F3/F4 consistency class in accordance with EN 206-1, as shown in Figure 1. In order to facilitate proper stability and homogeneity of the fresh mix with the foam bubbles, a viscosity-enhancing admixture (stabilizer ST3, Sika, Rosendahl, Germany) was added. Table 2 presents the proportions of the foamed concrete mixes.

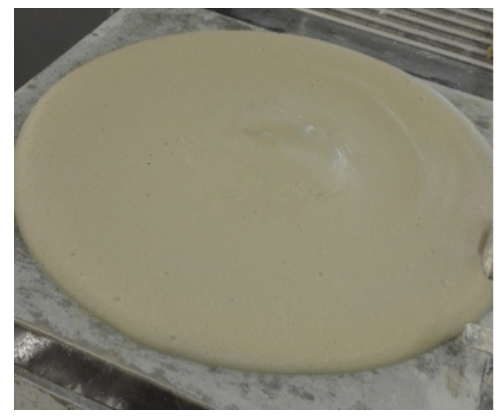

(a)

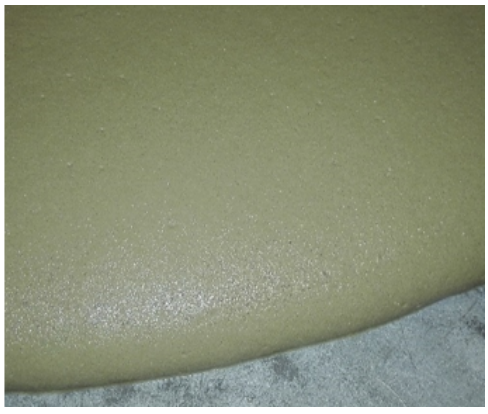

(b)

Figure 1. Confirmation of the consistency of the used foamed concrete (FCP): (a) general flow test, (b) magnification of the edge.

Table 1. Chemical composition and physical properties of the used cement and fly ash [wt.\%].

\begin{tabular}{ccccccccccc}
\hline Material & $\mathrm{CaO}$ & $\mathrm{SiO}_{2}$ & $\mathrm{Al}_{2} \mathrm{O}_{3}$ & $\mathrm{Fe}_{2} \mathrm{O}_{3}$ & $\mathbf{M g O}$ & $\mathbf{N a}_{2} \mathbf{O}$ & $\mathbf{K}_{2} \mathbf{O}$ & $\mathbf{S O}_{3}$ & Density $\left[\mathbf{k g} / \mathbf{m}^{3}\right]$ & $\begin{array}{c}\text { Surface Area }\left[\mathrm{m}^{2} / \mathbf{k g}\right] \\
(\text { Blaine) }\end{array}$ \\
\hline CEM I 52.5 R & 65.9 & 20.5 & 3.2 & 4.8 & 1.4 & 0.1 & 0.4 & 2.7 & 3150 & 386 \\
Fly ash & 4.7 & 47.8 & 20.9 & 4.5 & 1.5 & 0.7 & 1.0 & 0.9 & 2270 & 293 \\
\hline
\end{tabular}

To produce the foam, a foam generator SG S9 (Sika GmbH, Rosendahl, Germany) was employed. In the manufacturing process and according to the provider, the foam should be produced continuously to guarantee stable foam bubbles. The applied water and air pressures were adopted at 3 and 2 bars, respectively, with the dosage of foaming agent of $2 \%$ to achieve a uniform and steady foam. The density of the foam was measured using $30 \mathrm{~L}$ bucket and it ranged between $33-35 \mathrm{~g} / \mathrm{L}$. To manufacture foamed 
concrete, cement slurry was produced then it is mixed with the preformed foam. The absence of coarse aggregates increases the possibility of clumps and agglomeration of fine materials when mixing with water. Therefore, a high-intensity mixer (Eirich Group, Hardheim, Germany) was used to mix the cement paste to ensure homogeneous distribution of particles and avoid agglomeration and clumps of fine materials. After manufacturing the paste, the required foam volume was produced and both were mixed using a concrete mixer (Zyklos, Freisbach, Germany) with $50 \mathrm{~L}$ capacity to produce foamed concrete. Fresh properties of concrete were measured; consistency using the flow table was determined by measuring the diameter of the concrete without jolting the table. The density of fresh concrete was measured according to EN 12350-6 using a 5 L bowel but without compaction. Foam bubbles are very light and very sensitive to temperature changes and any movements. Therefore, no compaction or vibration has been applied when filling the $10 \times 10 \times 10 \mathrm{~cm}^{3}$ molds. The concrete samples were kept at a chamber with controlled humidity and temperature until demolding after $24 \mathrm{~h}$. The curing process was performed at the climate chamber with a temperature of $21^{\circ} \mathrm{C}$ and relative humidity of $99 \%$ until the testing day.

Table 2. Mix compositions of foamed concrete.

\begin{tabular}{|c|c|c|c|c|c|c|c|}
\hline Mix & $\begin{array}{l}\text { Cement } \\
\left(\mathrm{kg} / \mathrm{m}^{3}\right)\end{array}$ & $\begin{array}{l}\text { Fly Ash } \\
\left(\mathrm{kg} / \mathrm{m}^{3}\right)\end{array}$ & $\begin{array}{c}\text { Liaver }^{\circledR} \\
\left(\mathrm{kg} / \mathrm{m}^{3}\right)\end{array}$ & $w / b$ & $\begin{array}{c}\text { Super } \\
\text { Plasticizer } \\
\left(\mathrm{kg} / \mathrm{m}^{3}\right)\end{array}$ & $\begin{array}{l}\text { Stabilizer } \\
\left(\mathrm{kg} / \mathrm{m}^{3}\right)\end{array}$ & $\begin{array}{l}\text { Foam:Paste } \\
\text { (vol.) }\end{array}$ \\
\hline FCP (pure foam) & 140 & 60 & - & 0.4 & 3.0 & 0.75 & $4: 1$ \\
\hline FCA (foam + LWA) & 210 & 90 & 50 & 0.4 & 1.8 & 0.90 & $3: 1$ \\
\hline
\end{tabular}

\subsection{Production of VIPS}

Several methods can be used to evacuate and produce VIP samples, [31-34]. These studies have confirmed that the evacuation pressure should be less than $0.1 \mathrm{mbar}$, so as to produce an effective vacuum insulation panel, and that the procedure for producing VIPs with a reliable quality is highly complicated. However, since the main objective of the present study was to investigate the effects of various core materials on VIP properties, the VIP manufacturing process was beyond the scope of the study. The used VIP specimens were produced by Vaku-Isotherm GmbH (Frankenberg, Germany), using developed lightweight foamed concrete samples as the core materials. Figure 2 shows a product made by Vaku-Isotherm $\mathrm{GmbH}$ with a core consisting mainly of silica (preferably fumed silica) [32,35]. The VIP specimens with lightweight concrete were manufactured using exactly the same procedure as in Figure $2 b$, with only the core materials being replaced with lightweight concrete specimens. For measurement, six samples from each mix with dimensions of $10 \times 10 \times 2 \mathrm{~cm}^{3}$ were prepared and tested, as shown in Figure 3. In this figure, the target VIP sample (Figure 3a) and its internal features (Figure $3 b$ ) are presented. To produce a more effective VIP sample, the foamed concrete specimen was covered with double-layered felt and sealed with a metalized plastic film. The obtained VIP system was almost identical to the commercial product in Figure 2.

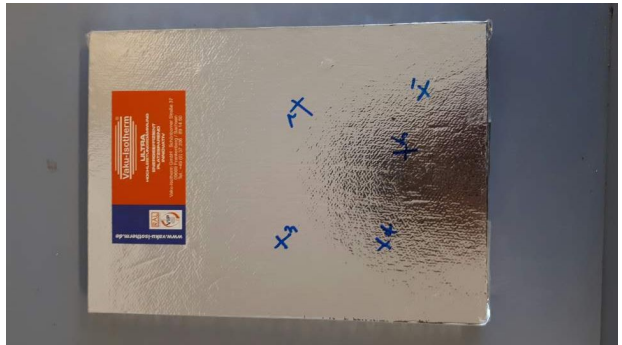

(a)

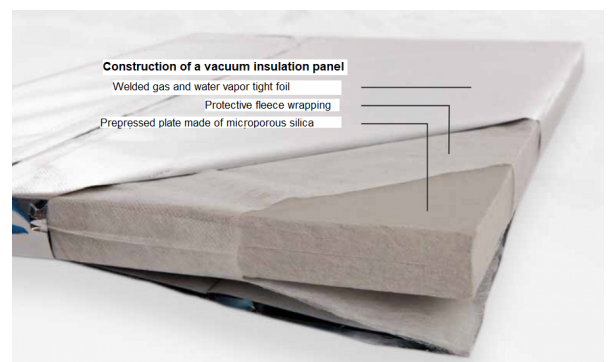

(b)

Figure 2. Commercial vacuum insulation panel (VIP) produced by Vaku-Isotherm GmbH (Frankenberg, Germany): (a) general product, (b) structure of the VIP. 


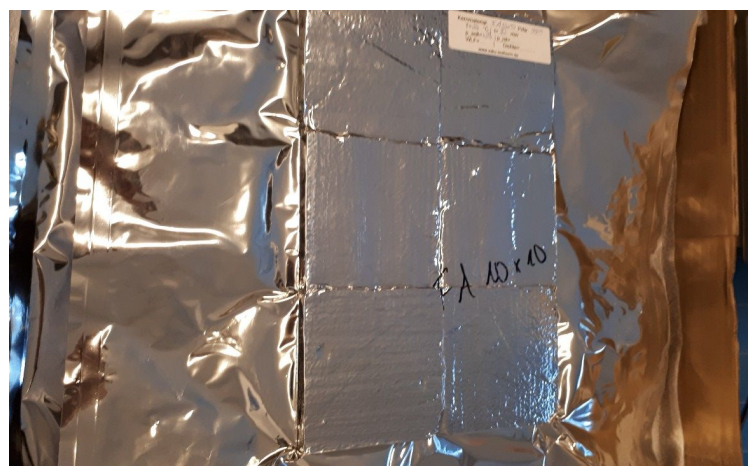

(a)

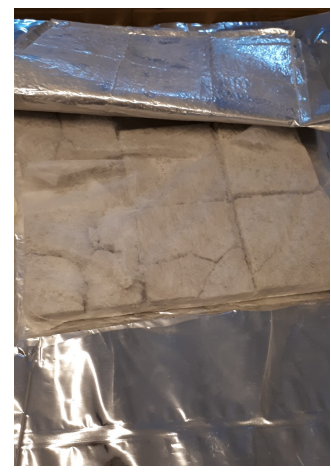

(b)

Figure 3. Evacuated foamed concrete (VIP): (a) VIP sample (FCP), (b) Inside of the VIP sample.

\section{Evaluation of Thermal Properties and Microstructures}

The most important function of VIPs is to enhance the thermal insulation of buildings or structures, with the thermal properties of target materials, such as thermal conductivity, being potential parameters for evaluating VIP performance. In this study, the thermal conductivity of the VIP specimens before and after evacuation was investigated experimentally and numerically. Two standardized experimental methods were used for accurate measurement, while numerical simulation was performed using micro-CT images. The microstructural characteristics of the core materials were also evaluated with the micro-CT data.

\subsection{Experimental Measurement}

For thermal conductivity measurements to compare insulation performance before and after evacuation, two methods were used to enhance accuracy and to confirm the influence of evacuation on the thermal characteristics of lightweight concrete: the Hot Disk device that satisfies ISO 22007-2 and the hot plate method, according to EN 12667. Both devices satisfy the necessary standards and have been widely used to measure the thermal properties of various objects, including construction materials [25,36-38].

Figure 4 shows the measurement processes using the Hot Disk (a) and the hot plate (b) methods. From the Hot Disk device, thermal properties, such as specific heat, thermal diffusivity and thermal conductivity, can be effectively and efficiently obtained without complex procedures. For the measurement, a sensor, used as a current supplier and temperature monitor, was positioned between the samples, as shown in Figure 4a; thermal properties can be calculated based on temperature change information [39].

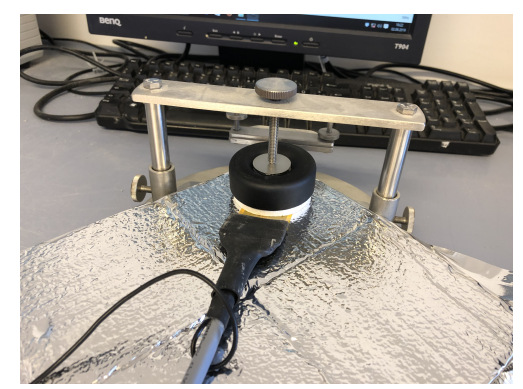

(a)

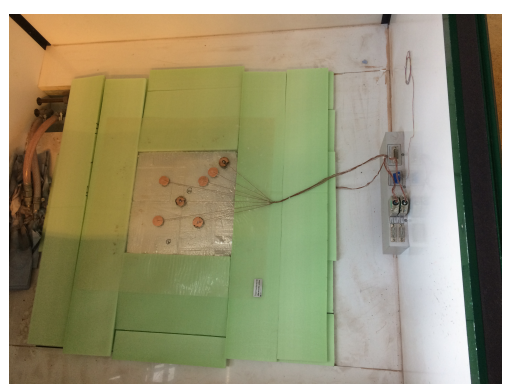

(b)

Figure 4. Experimental measurements of thermal conductivity: (a) the Hot Disk device, (b) the hot plate method.

The other method, the hot plate method in Figure $4 \mathrm{~b}$, is a standardized approach for measuring the thermal conductivity of target materials. In this method, a sample with a reference material 
is placed on the top of a calorimetric chamber, with the heat applied from underneath. Based on the known thermal conductivity of the reference material and the heat flux that passes through the two layers, the thermal conductivity of the target material can be ascertained [40,41]. The obtained results using both devices were compared to confirm accuracy and were used for numerical analysis, as input parameters.

\subsection{Micro-CT Investigation}

The lightweight concrete specimens used in this study are highly porous materials, with their pore characteristics strongly affecting their material properties. In particular, the pore structures of VIP core materials are some of the most critical factors in determining VIP performance, and an appropriate analysis is needed. For this purpose, X-ray micro-CT was used here. Micro-CT is a non-destructive method which can be used to visualize the internal microstructure of a target material; both 2D and $3 \mathrm{D}$ geometric characteristics can be examined using micro-CT images [28-30]. The used micro-CT device is self-made which consists of a Hamamatsu microfocus X-ray source and flat panel detector. The goniometers are from Huber ${ }^{\circledR}$ (Rimsting, Germany). In detail, the imaging system consists of a closed, air-cooled microfocus X-ray source (spot size 5-50 $\mu \mathrm{m}$ depending on voltage and current) from Hamamatsu ${ }^{\circledR}$ with up to $150 \mathrm{kV}$ voltage and $500 \mu \mathrm{A}$ current, corresponding to a power of $75 \mathrm{~W}$, and a flat panel detector is also from Hamamatsu ${ }^{\circledR}[42]$ (Shizuoka, Japan).

Figure 5 shows an image process for classifying the pore and solid from the FCP and FCA specimens, used for the characterization of the materials. The samples for the micro-CT measurement were selected from the whole specimen which used as a core material of the VIP sample. Cubes of $20 \mathrm{~mm}$ edge dimensions were scanned, and a total of 600 slices were recorded. The 1st and 2 nd images are the original 8-bit micro-CT image and its region of interest (ROI), respectively. Among the images of the whole specimen, for more effective description, the region of interest (ROI) with $400 \times 400 \times 200$ voxels $(x \times y \times z)$ was selected, which can be considered as representative volume of the specimens. The ROIs and the binary images in Figure 5 are composed of $400 \times 400$ pixels with $29.8 \mu \mathrm{m} /$ pixel. To segment the pores from the ROIs, a threshold was selected using the Otsu method [43] and manual confirmation, with the binary image being generated using the thresholding methods and the imaging toolbox in MATLAB (R2019b) [44]. In the binary image of the FCP specimen, which is pure foamed concrete, the black represents the pores, and the white represents the solid phase. For the FCA specimen, the segmentation is more complex because of the lightweight aggregates in the material. As can be seen in the lower images in Figure 5, lightweight aggregate particles have a more rigid solid than the matrix, which are described in light and dark grayscale according to their relative densities, respectively. This indicates that the aggregate solids are denser than the matrix and have different characteristics and properties. The segmentation of pores, aggregates, and the matrix was conducted using a multi-level thresholding approach [25,45]. As shown in Figure 6, the converted images were subsequently stacked, and the obtained 3D images were utilized for characterization and numerical analysis.

\subsection{Numerical Analysis}

The thermal conductivity of the VIP specimens was also computed using numerical simulation; commercial finite element analysis software, ABAQUS, was used for the analysis [46]. In the heat transfer analysis, the modified governing equation in $3 \mathrm{D}$ is described as follows [47]:

$$
\frac{\partial T}{\partial t}=\frac{k}{\rho C}\left(\frac{\partial^{2} T}{\partial x^{2}}+\frac{\partial^{2} T}{\partial y^{2}}+\frac{\partial^{2} T}{\partial z^{2}}\right)-\lambda \cdot T^{*}
$$

where $T[\mathrm{~K}]$ is the temperature, $T^{*}[\mathrm{~K}]$ is the surrounding temperature, $t[\mathrm{~s}]$ is the time, $k[\mathrm{~W} / \mathrm{m} / \mathrm{K}]$ is the thermal conductivity, $\rho\left[\mathrm{kg} / \mathrm{m}^{3}\right]$ is the mass density, and $C[\mathrm{~J} / \mathrm{g} / \mathrm{K}]$ is the specific heat. In this formulation, heat loss is considered using the heat loss coefficient, $\lambda[1 / \mathrm{s}]$. 
A weak form of the governing equation can be obtained by integrating Equation (1). Effective heat flux $(q)$ is obtained by averaging the heat flux of each element, with the effective thermal conductivity $(k)$ then expressed from Fourier's law, as follows:

$$
k=q \cdot L / \triangle T
$$

where $L$ is the characteristics length of the specimen, and $\triangle T$ is the temperature difference in the heat flow direction.

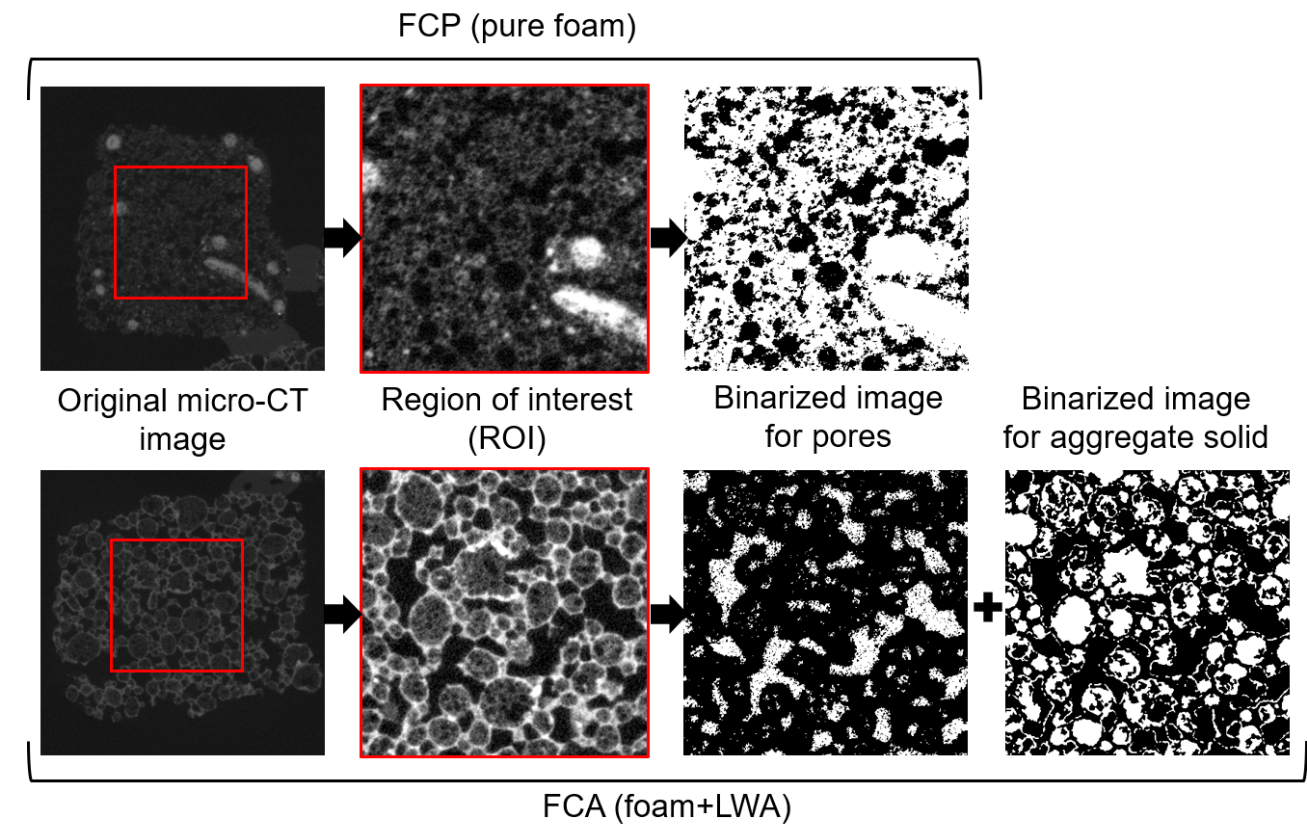

Figure 5. The procedure of micro-CT imaging for the specimens (Note: the 1st figures in both the FCP and FCA specimens are original 8-bit CT images, and the 2nd figures are of the region of interest (ROI) selected from the 1st images. The 3rd images are the segmented images of pores. For the FCP specimen, black represents pores, while white represents the background. In contrast, in the 3rd image of the FCA specimen, the white are pores, and the black is solid including lightweight aggregates. In the 4th FCA image, the white region represents the solid parts of the lightweight aggregates).

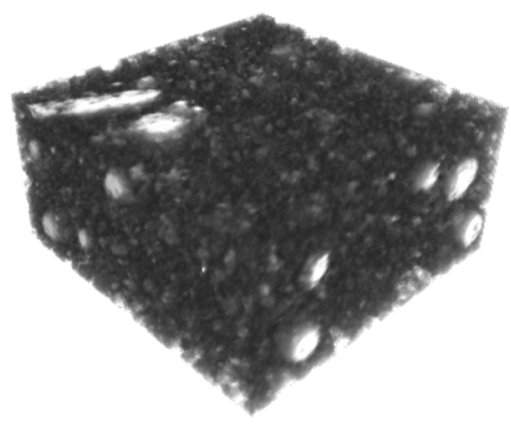

FCP specimen (pure foam)

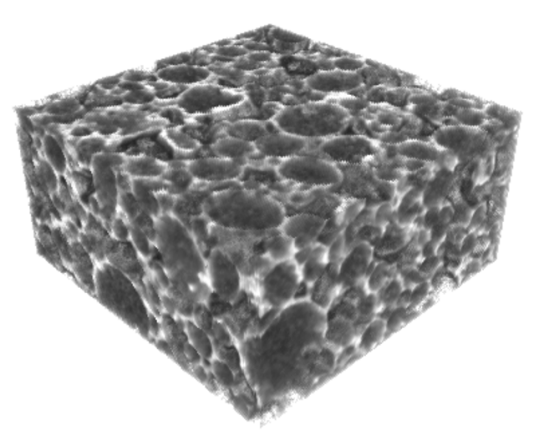

FCA specimen (foam+lightweight aggregates)

Figure 6. 3D micro-CT image of the core materials.

For the thermal analysis, the input bulk parameters (specific heat and thermal conductivity) were obtained experimentally. In particular, the total thermal conductivity of VIPs $\left(\lambda_{t o t}\right)$ is composed of several contributions, as follows [48,49]:

$$
\lambda_{\text {tot }}=\lambda_{\text {solid }}+\lambda_{\text {gas }}+\lambda_{\text {rad }}
$$


in Equation (3), $\lambda_{\text {solid }}$ is the solid thermal conductivity, $\lambda_{\text {gas }}$ is the gas thermal conductivity, and $\lambda_{\text {rad }}$ is the radiation thermal conductivity. Here, $\lambda_{\text {solid }}$ is the thermal conductivity of the bulk material, and $\lambda_{\text {gas }}$ is the thermal conductivity of air. For a more detailed analysis, $\lambda_{\text {rad }}$ also needs to be considered, because radiation effects are found in pores larger than a few micrometers. The value can be calculated using formula [50], with $\lambda_{\text {rad }}$ of $0.01[\mathrm{~W} / \mathrm{m} / \mathrm{K}]$ being used. The used input parameters for the thermal analysis are presented in Table 3. In this table, the density of the aggregates was provided by the manufacturer, and the other properties, such as thermal conductivity and specific heat, were measured using the Hot Disk device. In the case of evacuation, the thermal conductivity of air was set at zero. For boundary conditions, a constant temperature applied to the top surface and a surrounding temperature were set to be $60^{\circ} \mathrm{C}$ and $26^{\circ} \mathrm{C}$, respectively. The bottom surface was considered to have heat loss with a heat loss coefficient of 1.7 [1/s], while the other remaining surfaces were considered to have no heat loss.

Table 3. The input parameters for the heat transfer analysis.

\begin{tabular}{ccccc}
\hline Specimen & Material & $\begin{array}{c}\text { Thermal } \\
\text { Conductivity } \\
{[\mathbf{W} / \mathbf{m} / \mathbf{K}]}\end{array}$ & $\begin{array}{c}\text { Density } \\
{\left[\mathbf{k g} / \mathbf{m}^{3}\right]}\end{array}$ & $\begin{array}{c}\text { Specific } \\
\text { Heat } \\
{[\mathbf{J} / \mathbf{k g} / \mathbf{K}]}\end{array}$ \\
\hline FCP (pure foam) & Matrix & 0.205 & 519 & 1216 \\
\hline FCA (foam + LWA) & Matrix & 0.247 & 614 & 1075 \\
& Aggregates & 0.075 & 350 & 1150 \\
\hline - & Air (pore) & 0.035 & 1.225 & 1005 \\
\hline (Note: the thermal conductivity of air is $\lambda_{\text {tot }}$, where $\lambda_{\text {rad }}$ is set to be $\left.0.01[\mathrm{~W} / \mathrm{m} / \mathrm{K}]\right)$.
\end{tabular}

\section{Results and Discussion}

The performance of the VIPs with lightweight concrete cores were investigated using the thermal conductivity of the specimens. Both experiments and simulations were conducted to evaluate the thermal conductivity of the specimens, with the effects of the core materials being examined based on their thermal properties.

\subsection{Experimental Results}

The measured VIP thermal conductivity values are presented in Tables 4 and 5. Table 4 presents the results from the Hot Disk device, while Table 5 shows the result from the hot plate method. All measurements were performed three to five times for each specimen to enhance accuracy, with only the mean values presented here. In the Hot Disk method, three different points were selected, with the thermal conductivity being measured at certain points for a more accurate comparison. Although some differences between measurements are evident, it is clearly visible in Table 4 that the thermal conductivity values before and after evacuation were different. The difference is due to the heterogeneity of the lightweight concrete used as the core material. The thermal conductivity values before and after evacuation are more clearly different in the FCP specimen, which had a lower density and a more porous structure than the FCA specimen. In the FCP specimen, it can be seen that thermal conductivity reduced from 16.45 to $27.74 \%$ by evacuation, while the FCA specimen showed a thermal conductivity reduction of about $10 \%$. In general, foamed concrete has more pores than lightweight aggregates, with lower porosity affecting the efficiency of evacuation.

A similar trend can be found in the results of the hot plate method. In Table 5, the FCP specimen shows a $26.64 \%$ difference in thermal conductivity, while the thermal conductivity of the FCA specimen reduced by $6.64 \%$. Both the Hot Disk and the hot plate methods therefore confirmed that the use of lightweight concrete for the core material can reduce VIP thermal conductivity. Moreover, pure foamed concrete, which is a more porous material, is more effective in enhancing insulation performance via evacuation. In the tables, the thermal conductivity results of the Hot Disk and the hot plate method show a difference. In particular, thermal conductivity is almost double for the FCP specimen; this 
being due to the measurement capacity of each method, with the hot plate method being able to detect a wider range of thermal conductivity, according to the standard and the manufacturer. In addition, the heterogeneity of the core materials also affects thermal conductivity differences. The Hot Disk results are from specific points, while the results of the hot plate method are of the whole plate specimen; the hot plate method can therefore be considered to be more representative. Nevertheless, both of these standardized measurements show clear differences between before and after evacuation, with the effect of a vacuum being clearly confirmed when lightweight concrete was used as the core material.

Table 4. Thermal conductivity from the Hot Disk device.

\begin{tabular}{|c|c|c|c|c|c|}
\hline \multirow{2}{*}{ Material } & \multirow{2}{*}{$\begin{array}{l}\text { Oven-Dry Density } \\
\qquad\left(\mathrm{kg} / \mathrm{m}^{3}\right)\end{array}$} & \multirow{2}{*}{ Point } & \multicolumn{2}{|c|}{ Thermal Conductivity (W/m/K) } & \multirow{2}{*}{$\begin{array}{c}\text { Difference } \\
(\%)\end{array}$} \\
\hline & & & Evacuated & Air-Entrained & \\
\hline \multirow{3}{*}{ FCP (pure foam) } & \multirow{3}{*}{270} & 1 & 0.1086 & 0.1288 & $20.60 \%$ \\
\hline & & 2 & 0.0936 & 0.1090 & $16.45 \%$ \\
\hline & & 3 & 0.0918 & 0.1173 & $27.74 \%$ \\
\hline \multirow{3}{*}{ FCA (foam + LWA) } & \multirow{3}{*}{386} & 1 & 0.0972 & 0.1073 & $10.35 \%$ \\
\hline & & 2 & 0.1012 & 0.1100 & $8.70 \%$ \\
\hline & & 3 & 0.0972 & 0.1091 & $10.90 \%$ \\
\hline
\end{tabular}

Table 5. Thermal conductivity from Hot Plate method and compressive strength.

\begin{tabular}{|c|c|c|c|c|c|}
\hline \multirow{2}{*}{ Material } & \multirow{2}{*}{$\begin{array}{l}\text { Oven-Dry Density } \\
\qquad\left(\mathrm{kg} / \mathrm{m}^{3}\right)\end{array}$} & \multicolumn{2}{|c|}{ Thermal Conductivity (W/m/K) } & \multirow{2}{*}{$\begin{array}{c}\text { Difference } \\
(\%)\end{array}$} & \multirow{2}{*}{$\begin{array}{l}\text { Compressive } \\
\text { Strength (MPa) }\end{array}$} \\
\hline & & Evacuated & Air-Entrained & & \\
\hline FCP (pure foam) & 270 & 0.04868 & 0.06165 & $26.64 \%$ & 1.3 \\
\hline FCA (foam + LWA) & 386 & 0.07422 & 0.07915 & $6.64 \%$ & 2.4 \\
\hline
\end{tabular}

\subsection{Numerical Investigation}

For a more detailed analysis of evacuation performance, numerical characterization and simulation were also performed. Thermal simulation was performed using the 3D micro-CT image in Figure 6 by converting it into finite element meshes. Figure 7 shows the finite element meshes of the FCP and FCA specimens. For the FCP specimen, the whole specimen was classified into pore and solid parts, while the FPA specimen was divided into three phases: pore, binder, and aggregate solid.

The pore structures which strongly affect material properties were investigated using the pore part of each specimen. Based on the used pixel (voxel) resolution, the minimum pore size taken into consideration here was $29.8 \mu \mathrm{m}$, with the porosity and pore size distribution being computed using the voxel volume-based information, assuming all the pores were spherical [51,52]. Thus, the pores with the volume less than the image resolution were neglected, and this can affect relatively lower porosity than the actual value due to the limited resolution of the used images. The measured porosity of each specimen was $31.17 \%$ (FCP) and $16.00 \%$ (FCA). The pore size distributions of the used specimens are presented in Figure 8. In this figure, the total area of the pore size distribution for the FCP specimen is about twice that of the FCA specimen, which is consistent with the porosity trend. In particular, this tendency is more clear for pores larger than $50 \mu \mathrm{m}$; the relatively large pores clearly existed in the FCP specimen, while the FCA specimen had a higher proportion of smaller pores $(<50 \mu \mathrm{m})$. This indicates that pore foamed concrete tended to include larger pores, and that material with lightweight aggregates contained numerous smaller pores since the binder was filled with aggregate particles that include fine pores inside the materials. The measured characteristics confirmed that the general pore structure of foamed concrete can vary, depending on the inclusion of lightweight aggregates. 


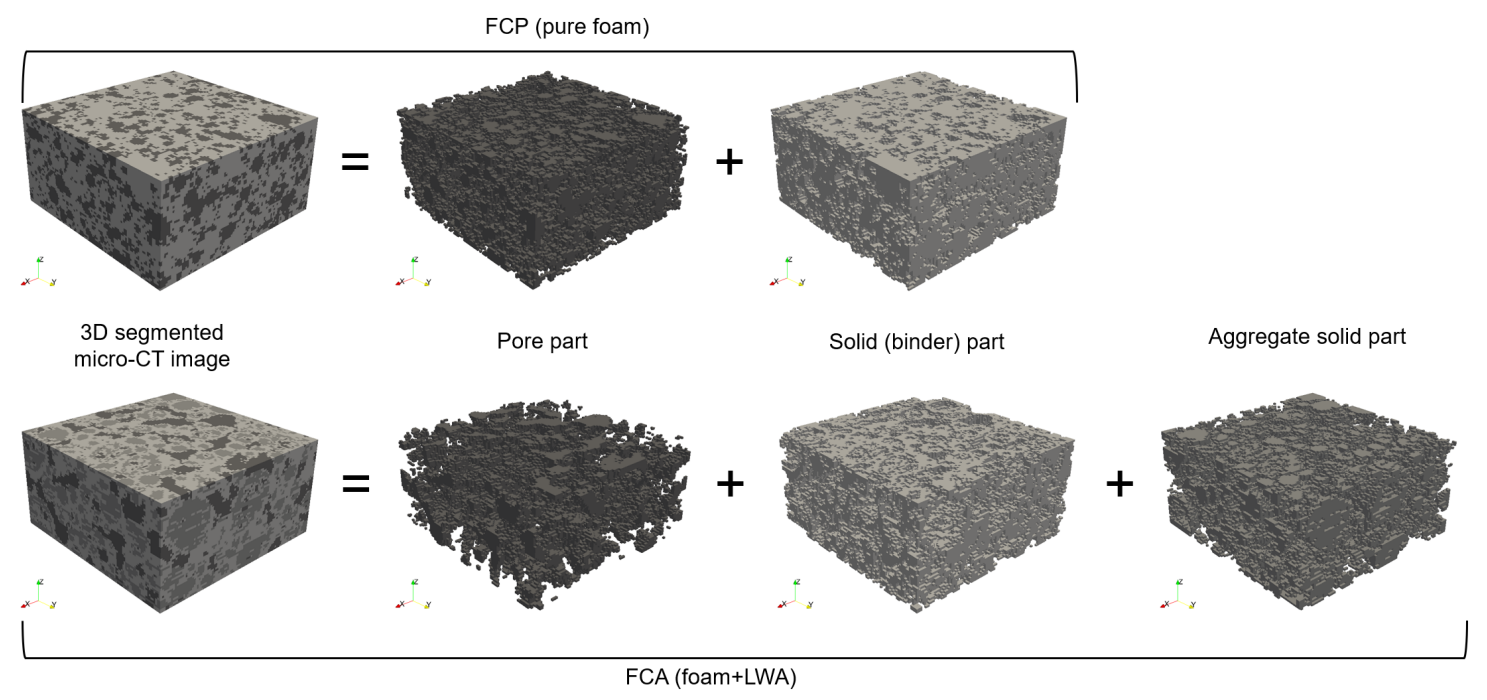

Figure 7. Finite element mesh of the core materials.

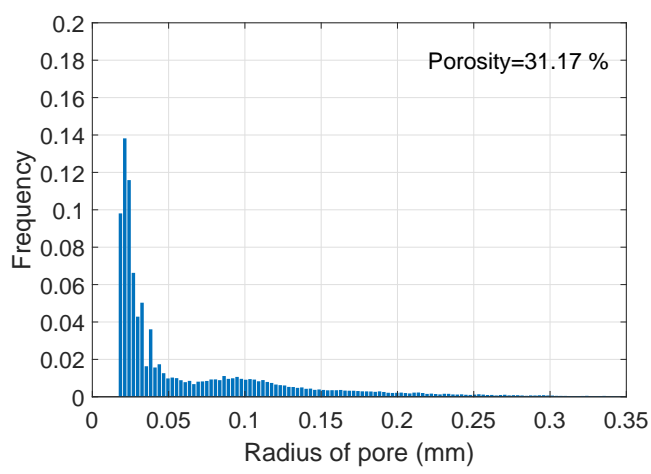

(a)

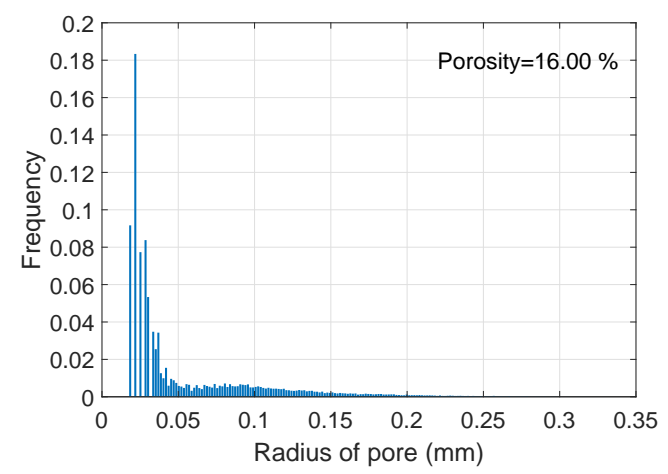

(b)

Figure 8. Pore size distribution of the core materials: (a) FCP specimen, (b) FCA specimen.

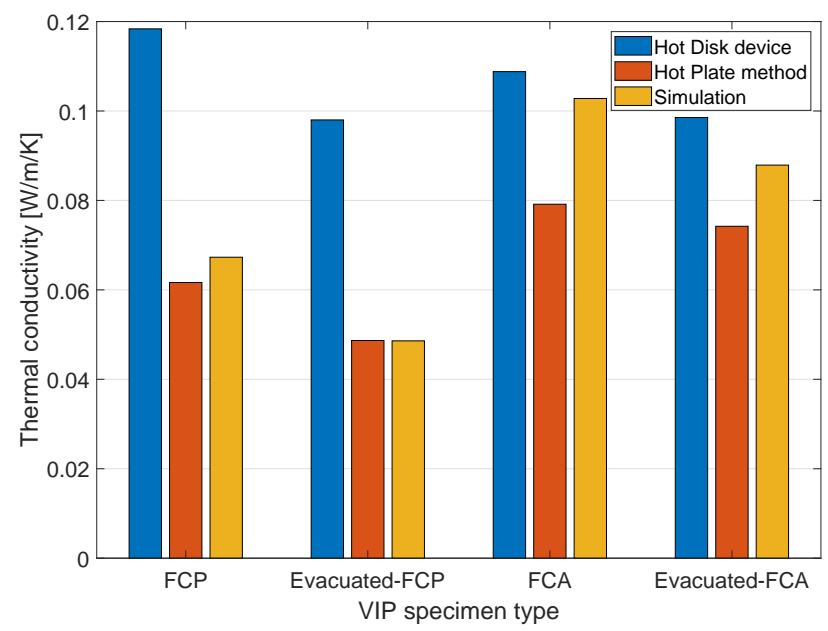

Figure 9. Thermal conductivity of the specimens measured from different approaches.

The numerical analysis for evaluating the thermal conductivity of the specimens was performed using the meshes in Figure 7 and the input parameter introduced in Table 3. The meshes were composed of $400 \times 400 \times 200(x \times y \times z)$ elements. Figure 9 shows thermal conductivity measured with different approaches, including the experiments in Section 4.1. Both the experiments, the numerically computed thermal conductivity results showed a similar trend; evacuated samples presented lower 
thermal conductivity than the normal cases, with the difference being clearer in the FCP specimen. The difference was due to the pore properties before and after evacuation. As shown in Table 3, the input thermal conductivity of the pore was lower than that of other solid components and less than half of the lightweight aggregates. In a simulation for the evacuated case, the input value was disregarded, and the effects of the vacuum resulted from the properties of the air. In addition, the porosity affected the degree of thermal conductivity decrease after evacuation. Since the FCA specimen contained less and smaller pores than the FCP specimen, the vacuum effect was less clear than in the specimen with larger and more pores.

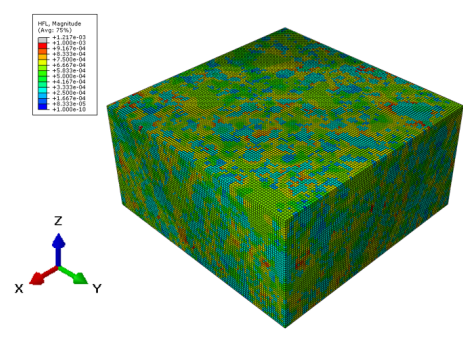

FCP mesh before evacuation

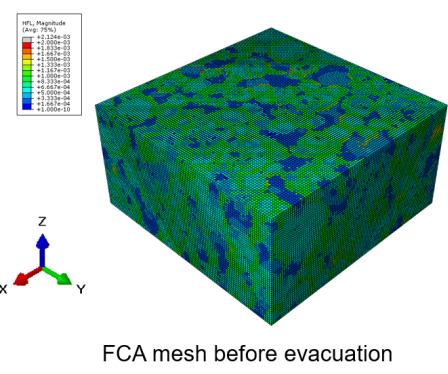

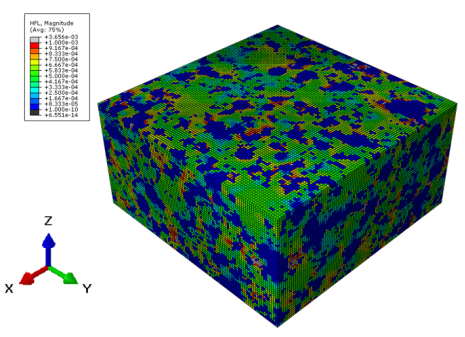

FCP mesh after evacuation

(a)

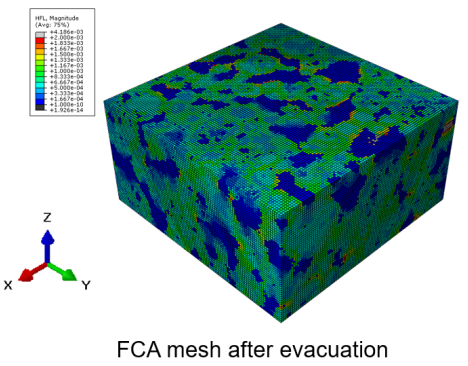

(b)

Figure 10. Heat flux contour of the core materials: (a) FCP specimen, (b) FCA specimen.
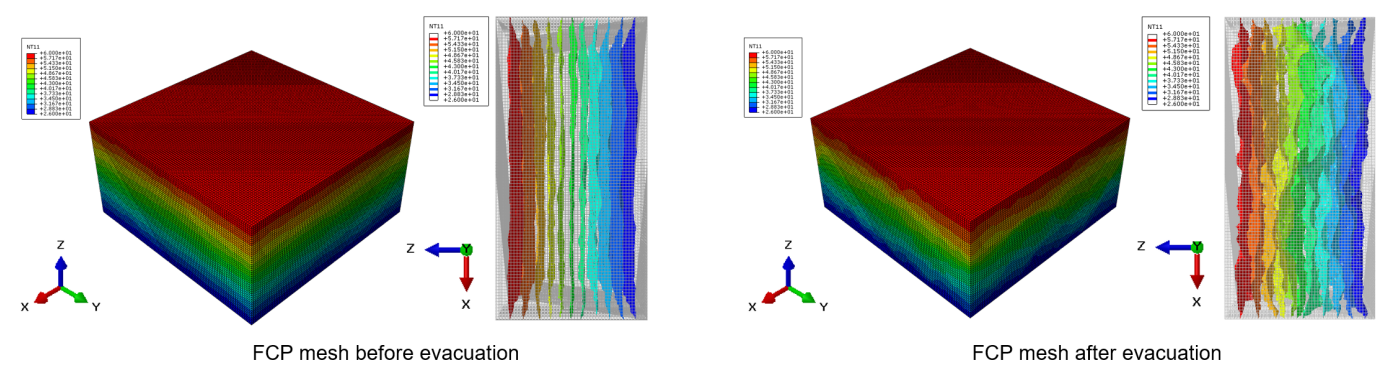

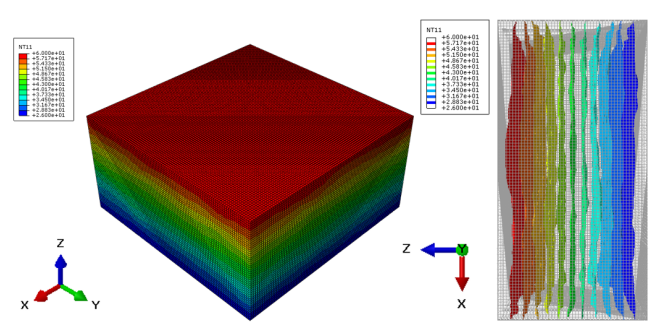

FCA mesh before evacuation (a)

)

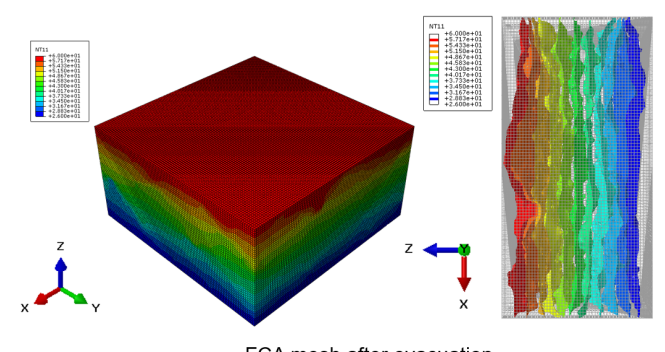

(b)

Figure 11. Temperature contour (left) and temperature isosurface (right) of the core materials: (a) FCP specimen, (b) FCA specimen. 
A detailed investigation of the numerical analysis can be found in Figures 10 and 11. Figure 10 shows the heat flux contour of the specimen before and after evacuation. In each figure, the left image presents the heat flux contour in the normal state, while the image on the right is the heat flux contour of the specimen under vacuum. In these figures, the blue color depicts almost no heat flows in that region. Comparing the images before and after the evacuation, the blue areas were clearer in the vacuum state, since no heat transfer occurred through the pores, with this phenomenon being distinct in the FCP specimen, which had larger porosity and pore size. The effects of evacuation can also be examined in Figure 11. Like the heat flux images, the left and right images of Figure 11 show a temperature contour and its isosurface before and after the vacuum, respectively. In both the FCP and FCA specimens, less fluctuation can be seen in the case of the natural state, while many fluctuations can be found in the vacuum state on the right side, particularly in the vicinity of the pores. Moreover, the difference in fluctuation is more pronounced in the case of the FCP specimen, which contained more and larger pores.

The obtained results confirm that both pure foamed and foamed concrete incorporating lightweight aggregates show a clear difference before and after evacuation. Moreover, it is clear that lightweight concrete of low density, with/without lightweight aggregates, can be effectively used as a VIP core material since it contains numerous pores and has sufficient strength. In addition, the pore structures within the core materials strongly affect the efficiency of evacuation, with a material with large porosity as well as pore size able to be beneficial for achieving better vacuum effects.

\section{Conclusions}

This study aimed to investigate the applicability of lightweight foamed concrete with a low density $\left(270 \mathrm{~kg} / \mathrm{m}^{3}\right.$ and $\left.386 \mathrm{~kg} / \mathrm{m}^{3}\right)$ as a core material for VIPs. For this purpose, lightweight concrete specimens, pure foamed concrete (FCP) and foamed concrete with lightweight aggregates (FCA), were designed and prepared. The thermal conductivity of the produced specimens was measured both experimentally and numerically, as a parameter for evaluating the effects of evacuation. For a more accurate analysis, two types of standard experimental devices were used and compared. The experimental results were utilized in numerical analysis as input parameters. Micro-CT was also used to visualize and characterize the pore structure of the specimens, with the numerical simulation being performed using the meshes obtained from the CT images.

The concluding remarks of this study are summarized below, as follows:

- Different experimental and numerical approaches show similar trends in the effects of evacuation on lightweight concrete. In both FCP and FCA specimens, regardless of small differences between methods, the FCP specimen showed a lower thermal conductivity than the FCA specimen, with the thermal conductivity clearly decreasing in the vacuum state for both specimens. It is thus confirmed that foamed concrete with a density below $390 \mathrm{~kg} / \mathrm{m}^{3}$, with or without aggregates, can be effectively used as a core VIP material.

- The evacuation of lightweight concrete specimens shows a clear effect on insulation, up to a maximum of about $28 \%$. In particular, specimens with less density and more pores shows a clear difference before and after evacuation.

- Pore characteristics, such as porosity and pore size distribution, affect the efficiency of a vacuum. Comparing the cases used in this study, a material with larger porosity and pore size is beneficial in achieving better evacuation and insulation performances.

- Pure foamed concrete with a lower density shows better vacuum efficiency for use as a core VIP material. However, it tends to break during preparation and measurements because of the high evacuation pressure needed for VIP production. To enhance vacuum efficiency, the use of specimens with lower densities but higher strengths is recommended; this can be achieved by using lightweight aggregates or other binders. 
In addition, further investigation of the relationship between material characteristics (e.g., pore and solid structures) and evacuation effects needs to be performed. Moreover, parametric studies using different lightweight concretes could be conducted to figure out the effectiveness of lightweight concretes as core VIP materials.

Author Contributions: S.-Y.C. and D.S. conceived and designed the experiments; M.A.E. performed the experiments; S.-Y.C. and P.S. analyzed the data; P.S. and M.A.E. contributed materials and analysis tools; S.-Y.C., P.S., and M.A.E. wrote the paper. All authors have read and agreed to the published version of the manuscript.

Funding: The project was supported by the German Federal Ministry of Education and Research (BMBF, Project Number: 13XP5010B). This work was also supported by the Korea Agency for Infrastructure Technology Advancement(KAIA) grant funded by the Ministry of Land, Infrastructure and Transport (Grant 20NANO-B156177-01). In addition, this project was received funding from the European Union's Horizon 2020 research and innovation program under the Marie Skłodowska-Curie Grant agreement no. 841592. P.S. is supported by the Foundation for Polish Science (FNP).

Conflicts of Interest: The authors declare no conflicts of interest.

\section{References}

1. Lorenzati, A.; Fantucci, S.; Capozzoli, A.; Perino, M. Experimental and numerical investigation of thermal bridging effectsof jointed Vacuum Insulation Panels. Energy Build. 2016, 111, 164-175. [CrossRef]

2. Choi, B.; Song, T.-H. Investigation of edge taping method applied to vacuum insulationpanels. Energy Build. 2017, 134, 52-60. [CrossRef]

3. Benmansour, N.; Agoudjil, B.; Gherabli, A.; Kareche, A.; Boudenne, A. Thermal and mechanical performance of natural mortar reinforced with date palm fibers for use as insulating materials in building. Energy Build. 2014, 58, 98-104. [CrossRef]

4. Zhang, Z.; Provis, J. L.; Reid, A.; Wang, H. Mechanical, thermal insulation, thermal resistance and acoustic absorption properties of geopolymer foam concrete. Cem. Concr. Compos. 2015, 62, 97-105. [CrossRef]

5. Binici, H.; Aksogan, O.; Demirhan, C. Mechanical, thermal and acoustical characterizations of an insulation composite made of bio-based materials. Sustain. Cities Soc. 2016, 20, 17-26. [CrossRef]

6. Uriarte, A.; Garai, I.; Ferninando, A.; Erkoreka, A.; Nicolas, O.; Barreiro, E. Vacuum insulation panels in construction solutions for energy efficient retrofitting of buildings. Two case studies in Spain and Sweden. Energy Build. 2019, 197, 131-139. [CrossRef]

7. Menyhart, K.; Krarti, M. Potential energy savings from deployment of Dynamic Insulation Materials for US residential buildings. Build. Environ. 2017, 114, 203-218. [CrossRef]

8. Abu-Jdayil, B.; Mourad, A.-H.; Hittini, W.; Hassan, M.; Hameedi, S. Traditional, state-of-the-art and renewable thermal building insulation materials: An overview. Constr. Build. Mater. 2019, 214, 709-735. [CrossRef]

9. Simmler, H.; Brunner, S. Vacuum insulation panels for building application.Basic properties, aging mechanisms and service life. Energy Build. 2005, 37, 1122-1131. [CrossRef]

10. Meersman, G.D.; Bossche, N.V.D.; Janssens, A. Long Term Durability of Vacuum Insulation Panels: Determination of the Sd-value of MF-2 Foils. Energy Procedia 2015, 78, 1574-1580. [CrossRef]

11. Alotaibi, S.S.; Riffat, S. Vacuum insulated panels for sustainable buildings: a review of research and applications. Int. J. Energy Res. 2013, 38, 1-19. [CrossRef]

12. Mehta, P.K.; Monteiro, P.J.M. Concrete: Microstructure, Properties and Materials, 4th ed.; McGraw-Hill: New York, NY, USA, 2015.

13. Chung, S.-Y.; Kim, J.-S.; Stephan, D.; Han, T.-S. Overview of the use of micro-computed tomography (micro-CT) to investigate the relation between the material characteristics and properties of cement-based materials. Constr. Build. Mater. 2019, 229, 116843. [CrossRef]

14. Baetens; R.; Jelle, B.P.; Thue, J.V.; Tenpierik, M.J.; Grynning, S.; Uvslokk, S.; Gustavesen, A. Vacuum insulation panels for building applications: A review and beyond. Energy Build. 2010, 42, 142-172.

15. Guo, H.; Guo, W.; Shi, Y. Computational modeling of the mechanical response of lightweight foamed concrete over a wide range of temperatures and strain rates. Constr. Build. Mater. 2015, 96, 622-631. [CrossRef] 
16. Cui, H.Z.; Lo, T.Y.; Memon, S.A.; Xing, F.; Shi, X. Analytical model for compressive strength, elastic modulus and peak strain of structural lightweight aggregate concrete. Constr. Build. Mater. 2012, 36, 1036-1043. [CrossRef]

17. Narayanan, N.; Ramamurthy, K. Structure and properties of aerated concrete: A review. Cem. Concr. Compos. 2000, 22, 321-329. [CrossRef]

18. Yu, R.; van Onna, D.V.; Spiesz, P.; Yu, Q.L.; Brouwers, H.J.H. Development of ultra-lightweight fibre reinforced concrete applying expanded waste glass. J. Clean. Prod. 2016, 112, 690-701. [CrossRef]

19. Ke, Y.; Beaucour, A.L.; Ortola, S.; Dumontet, H.; Cabrillac, R. Influence of volume fraction and characteristics of lightweight aggregates on the mechanical properties of concrete. Constr. Build. Mater. 2009, 23, 2821-2828. [CrossRef]

20. Chen, H.-J.; Yang, M.-D.; Tang, C.-W.; Wang, S.-Y. Producing synthetic lightweight aggregates from reservoir sediments. Const. Build. Mater. 2015, 28, 387-394. [CrossRef]

21. Youm, K.-S.; Moon, J.; Cho, J.-Y.; Kim, J. J. Experimental study on strength and durability of lightweight aggregate concrete containing silica fume. Constr. Build. Mater. 2016, 114, 517-527. [CrossRef]

22. Ramamurthy, K.; Nambiar, E.K.; Ranjani, G. A classification of studies on properties of foam concrete. Cem. Concr. Comp. 2009, 31, 388-396. [CrossRef]

23. Chung, S.-Y.; Lehmann, C.; Abd Elrahman, M.; Stephan, D. Pore Characteristics and Their Effects on the Material Properties of Foamed Concrete Evaluated Using Micro-CT Images and Numerical Approaches. Appl. Sci. 2017, 7, 550. [CrossRef]

24. Nguyen, T.T.; Bui, H.H.; Ngo, T.D.; Nguyen, G.D. Experimental and numerical investigation of influence of air-voids on the compressive behaviour of foamed concrete. Mater. Des. 2017, 130, 103-119. [CrossRef]

25. Chung, S.-Y.; Abd Elrahman, M.; Kim, J.-S.; Han, T.-S.; Stephan, D. Comparison of lightweight aggregate and foamed concrete with the same density level using image-based characterizations. Constr. Build. Mater. 2019, 211, 988-999. [CrossRef]

26. Nambiar, E.K.; Ramamurthy, K. Air-void characterisation of foam concrete. Cem. Concr. Res. 2007, 37, 221-230. [CrossRef]

27. Huang, Y.; Yang, Z.; Ren, W.; Liu, G.; Zhang, C. 3D meso-scale fracture modelling and validation of concrete based on in-situ X-ray Computed Tomography images using damage plasticity model. Int. J. Solids Struct. 2015, 67-68, 340-352. [CrossRef]

28. Chung, S.-Y.; Kim, J.-S.; Han, T.-S. Effects of Void Clustering on the Thermal and Mechanical Properties of Concrete Evaluated Using Numerical Methods. Multiscale Sci. Eng. 2019, 1, 1-14. [CrossRef]

29. Fukuda, D.; Nara, Y.; Kobayashi, Y.; Maruyama, M.; Koketsu, M.; Hayashi, D.; Ogawa, H.; Kaneko, K. Investigation of self-sealing in high-strength and ultra-low-permeability concrete in water using micro-focus X-ray CT. Cem. Concr. Res. 2012, 42, 1494-1500. [CrossRef]

30. Kim, J.-S.; Chung, S.-Y.; Stephan, D.; Han, T.-S. Issues on characterization of cement paste microstructures from $\mu$-CT and virtual experiment framework for evaluating mechanical properties. Constr. Build. Mater. 2019, 202, 82-102. [CrossRef]

31. Jung, H.; Yeo, I.; Song, T.-H. Al-foil-bonded enveloping and double enveloping for application to vacuum inisulation panels. Energy Build. 2014, 84, 595-606. [CrossRef]

32. Kalnaes, S.E.; Jelle, B.P. Vacuum insulation panel products: A state-of-the-art review and future research pathways. Energy Build. 2014, 116, 355-375. [CrossRef]

33. Li, C.-D.; Saeed, M.-U.; Pan, N.; Chen, Z.-F.; Xu, T.-Z. Fabrication and characterization of low-cost and green vacuum insulation panels with fumed silica/rice husk ash hybrid core material. Mater. Des. 2016, 107, 440-449. [CrossRef]

34. Liang, Y.; Wu, H.; Huang, G.; Yang, J.; Wang, H. Thermal performance and service life of vacuum insulation panelswith aerogel composite cores. Energy Build. 2017, 154, 606-617. [CrossRef]

35. Erb, M.; Pauli, E.; Brunner, S. Vacuum Insulation for Building Applications; Swiss Federal Office of Energy: Bern, Switzerland, 2014.

36. Abd Elrahman, M.; Chung, S.-Y.; Stephan, D. Effect of different expanded aggregates on the properties of lightweight concrete. Mag. Concr. Res. 2019, 71, 95-107. [CrossRef]

37. Jeong, Y.-W.; Koh, T.-H.; Youm, K.-S.; Moon, J. Experimental Evaluation of Thermal Performance and Durability of Thermally-Enhanced Concretes. Appl. Sci. 2017, 7, 811. [CrossRef] 
38. Li, P.; Wu, H.; Liu, Y.; Yang, J.; Fang, Z.; Lin, B. Preparation and optimization of ultra-light and thermal insulative aerogel foam concrete. Constr. Build. Mater. 2019, 205, 529-542. [CrossRef]

39. Hot Disk AB. Hot Disk Thermal Constants Analyser-Instruction Manual; Hot Disk AB: Uppsala, Sweden, 2014.

40. Jannot, Y.; Felix, V.; Degiovanni, A. A centered hot plate method for measurement of thermal properties of thin insulating materials. Meas. Sci. Technol. 2010, 21, 035106. [CrossRef]

41. Flori, M.; Putan, V.; Vilceanu, L. Using the heat flow plate method for determining thermal conductivity of building materials. Mater. Sci. Eng. 2017, 163, 012018. [CrossRef]

42. Moreno, F.G.; Fromme, M.; Banhart, J. Real-time X-ray radioscopy on metallic foams using a compact micro-focus source. Adv. Eng. Mater. 2004, 6, 416-420. [CrossRef]

43. Otsu, N. A threshold selection method from gray-level histograms. Man Cybern. 1979, 9, 62-66. [CrossRef]

44. MATLAB. R2019a; The MathWorks Inc.: Natick, MA, USA, 2019.

45. Huang, D.-Y.; Wang, C.-H. Optimal multi-level thresholding using a two-stage Otsu optimization approach. Pattern Recognit. Lett. 2009, 30, 275-284. [CrossRef]

46. ABAQUS. Version 6.13; Dassault Systemes: Pawtucket, RI, USA, 2013.

47. Chung, S.-Y.; Stephan, D.; Abd Elrahman, M.; Han, T.-S. Effects of anisotropic voids on thermal properties of insulating media investigated using 3D printed samples. Constr. Build. Mater. 2016, 111, 529-542. [CrossRef]

48. Kwon, J.S.; Jung, H.; Yeo, I.S.; Song, T. H. Outgassing characteristics of a polycarbonate core material for vacuum insulation panels. Vacuum 2011, 85, 839-846. [CrossRef]

49. Li, C.-D.; Chen, Z.-F.; Boafo, F.E.; Xu, T.-Z.; Wang, L. Effect of pressure holding time of extraction process on thermalconductivity of glassfiber VIPs. J. Mater. Process. Technol. 2014, 214, 539-543. [CrossRef]

50. De Walle, W.V.; Janssen, H. A thermal conductivity prediction model for porous building blocks. Bauphysik 2011, 38, 340-347. [CrossRef]

51. Chung, S.-Y.; Sikora, P.; Rucinska, T.; Stephan, D.; Abd Elrahman, M. Comparison of the pore size distributions of concretes with different air-entraining admixture dosages using 2D and 3D imaging approaches. Mater. Charact. 2020, 162, 110182. [CrossRef]

52. Patterson, B.M.; Escobedo-Diaz, J.P.; Dennis-Koller, D.; Cerreta, E. Dimensional quantification of embedded voids or objects in three dimensions using X-ray tomography. Microsc. Microanal. 2012, 18, 390-398. [CrossRef] [PubMed]

(C) 2020 by the authors. Licensee MDPI, Basel, Switzerland. This article is an open access article distributed under the terms and conditions of the Creative Commons Attribution (CC BY) license (http://creativecommons.org/licenses/by/4.0/). 